\title{
Synthesis, Characterization and Antifungal Activities of Adducts of Bis( $O$-isoamyldithiocarbonato)oxovanadium(IV) with Substituted Pyridines
}

\author{
NEERUPAMA*, DEEPSHIKHA KHAJURIA, POOJA SHARMA, \\ RAJINDER SINGH and RENU SACHAR
}

Department of Chemistry, University of Jammu, Babasaheb Ambedkar Road, Jammu-180006, India

neeru.s1211@rediffmail.com

Received 13 March 2014 / Accepted 2 June 2014

\begin{abstract}
A series of adducts of $\operatorname{Bis}(O$-isoamyldithiocarbonato)oxovanadium(IV) with substituted pyridines have been synthesized by treating $\mathrm{Bis}(\mathrm{O}$-amyldithiocarbonato)oxovanadium(IV) with substituted pyridines in acetone in equimolar ratios. Analytical results show that the adducts have 1:1 stoichiometry with general formula $\mathrm{VO}(\mathrm{O}$-isoamyldithiocarbonato $) 2 \mathrm{~L}$ where $\mathrm{L}=2$ and 3bromopyridine; 4-acetylpyridine; 3-hydroxypyridine; 2-methoxypyridine; 2-amino-3-methylpyridine; 2amino-4-methylpyridine; 2-amino-6-methylpyridine). The addition complexes have been characterized by elemental analysis, conductivity measurements, magnetic susceptibility measurements, infrared and electronic spectral studies. These studies suggest a distorted octahedral structure and paramagnetic nature of the adducts. Antifungal activity of some adducts have been carried out against the fungal strain Sclerotium rolfsii.
\end{abstract}

Keywords: Oxovanadium(IV), O-Isoamyltrithiocarbonato, Sclerotium rolfsii

\section{Introduction}

Xanthates (dithiocarbonates) have been known for a long time ${ }^{1,2}$ and many adducts of metal xanthates with different ligands have been prepared and studied in the last several decades ${ }^{3,4}$. In this paper, we select xanthate as the anion because of its ability to bind to various metals ${ }^{5,6}$. It forms a chelate with virtually all transition elements and has proved to be a versatile chelating agent for the separation and extraction of metals in analytical chemistry and mineral floating ${ }^{7,8}$. Metal xantahte complexes have low solubility products and high stability constants and therefore exhibit high efficiency for removal of metal ions. These are extensively used as fungicides, pesticides, rubber accelerator, corrosion inhibitors, agricultural reagents and quite recently in therapy for HIV infections ${ }^{9-11}$. Metal xanthate complexes and their reaction products with a variety of Lewis bases have been extensively studied $^{12-14}$ while transition metal xanthate complexes have been investigated for non linear optical properties ${ }^{15}$. 


\section{Experimental}

Potassium salt of isoamyl xanthate was prepared by the method reported in literature ${ }^{16}$. Into a $500 \mathrm{~mL}$ round bottomed flask, fitted with a reflux condenser, was placed $42 \mathrm{~g}(0.75 \mathrm{~mol})$ of potassium hydroxide pellets and $228.80 \mathrm{~g}(282.32 \mathrm{~mL}, 2.6 \mathrm{~mol})$ of isoamyl alcohol. The reaction mixture was heated under reflux for $1 \mathrm{~h}$. The mixture was then cooled and liquid from the residual solid was decanted off into another dry $500 \mathrm{~mL}$ flask. To this flask, was added $57 \mathrm{~g}(45 \mathrm{~mL}, 0.75 \mathrm{~mol})$ of carbon disulphide slowly with constant shaking. The residual solid mass was filtered (after cooling in ice) on a sintered glass funnel at the pump. It was washed with three $25 \mathrm{~mL}$ portions of ether. The resulting potassium $O$-isoamyldithiocarbonate (potassium salt of isoamyl xanthate) was dried in a vacuum dessicator over anhydrous calcium chloride. It was then recrystallized from absolute ethanol.

\section{Preparation of bis(O-isoamyldithiocarbonato)oxovanadium(IV)}

The saturated aqueous solutions of hydrated vanadyl sulfate $(1.63 \mathrm{~g}, 0.01 \mathrm{~mol})$ and potassium $O$-isoamyldithiocarbonate $(4.04 \mathrm{~g}, 0.02 \mathrm{~mol})$ were prepared separately and then mixed with constant stirring. Dark green precipitates were formed which were filtered immediately and were dried in a vacuum desiccator over anhydrous calcium chloride. The composition of the complex was established to be $\mathrm{VO}\left[\mathrm{S}_{2} \mathrm{C}\left(\mathrm{O}-\mathrm{C}_{5} \mathrm{H}_{11}\right)\right]_{2}$ by the elemental analysis.

\section{Preparation of 1:1 adducts of bis(O-isoamyldithiocarbonato)oxovanadium(IV) with nitrogen donors}

The 1:1 addition complexes of bis( $O$-isoamyldithiocarbonato)oxovanadium(IV) with substituted pyridines were prepared by stirring $\mathrm{VO}\left[\mathrm{S}_{2} \mathrm{C}\left(\mathrm{O}-\mathrm{C}_{5} \mathrm{H}_{11}\right)\right]_{2}(0.92 \mathrm{~g}, 0.0026 \mathrm{~mol})$ in acetone with substituted pyridines [2-bromopyridine $0.410 \mathrm{~g}$; 3-bromopyridine $0.410 \mathrm{~g}$; 4 acetylpyridine 0.314 ; 3-hydroxypyridine $0.247 \mathrm{~g}$; 2-methoxypyridine $0.287 \mathrm{~g}$; 2-amino-3methylpyridine $0.2511 \mathrm{~g} ; 2$-amino-4-methylpyridine $0.2511 \mathrm{~g} ; 2$-amino-6-methyl-pyridine $0.2511 \mathrm{~g}$ ] for $30 \mathrm{~min}$. The contents of the reaction mixture were allowed to stand for 20-24 h and the green obtained was washed with the solvent used in their preparation and dried over calcium chloride at room temperature.

\section{Methods}

Carbon, Hydrogen, Nitrogen and Sulfur were determined on elemental analyzer (elemental vario EL III, carlo Erba 1108). Molar conductance was determined on the millimolar solution in DMF using century CC 601 Conductivity Bridge. Infrared spectra of the complexes over the region 4,000-200 $\mathrm{cm} 21$ were recorded using $\mathrm{KBr}$ pellets on Infrared spectrophotometer (Perkin Elmer FT-IR). The electronic spectra of the adducts were recorded in DMF on systronics 119 UV-visible spectrophotometer. Magnetic moments were determined at room temperature by VSM method (Princeton Applied Research-Model No. 155). The analytical data, molar conductance and magnetic moments of the adducts isolated are presented in Table 1S. Important IR bands and electronic spectral data are cited in Table 2S

\section{Results and Discussion}

\section{Preliminary investigation}

The adducts of bis(O-isoamyldithiocarbonato)oxovanadium(IV) are microcrystalline solids and are characterised by various physicchemical techniques. These adducts are insoluble in common organic solvents such as benzene, acetone, toluene, 1,4-dioxane, nitrobenzene, ethanol etc. However these adducts are soluble in dimethylformamide and dimethylsulfoxide. The elemental analysis reveals that the adducts isolated have 1:1 stoichiometry depending upon the molar ratios of metal and ligand taken for their preparation (Table 1). 
Table 1. Analytical data of 1:1 adducts of bis(o-isoamylyldithiocarbonato)oxovanadium(IV) with substituted pyridines

\begin{tabular}{|c|c|c|c|c|c|c|c|c|c|c|c|}
\hline \multirow{2}{*}{ S.No. } & \multirow{2}{*}{\multicolumn{2}{|c|}{ Name of the adducts }} & \multirow{2}{*}{ Formula. } & \multicolumn{4}{|c|}{ \%age (Found) } & \multicolumn{4}{|c|}{ \%age (Calculated) } \\
\hline & & & & $\mathrm{C}$ & $\mathrm{H}$ & $\mathrm{N}$ & S & $\mathrm{C}$ & $\mathrm{H}$ & $\mathrm{N}$ & S \\
\hline 1 & \multicolumn{2}{|c|}{$\begin{array}{l}\operatorname{Bis}(O \text {-isoamyldithiocarbonato) } \\
\text { (2-bromopyridine)oxovanadium(IV) }\end{array}$} & $\begin{array}{l}\mathrm{VO}\left(\mathrm{S}_{2} \mathrm{COC}_{2} \mathrm{H}_{5}\right)_{2} \\
\quad\left(\mathrm{C}_{5} \mathrm{H}_{5} \mathrm{NBr}\right)\end{array}$ & 36.75 & 4.65 & 2.45 & 22.44 & 37.02 & 4.74 & 2.58 & 23.23 \\
\hline 2 & \multicolumn{2}{|c|}{$\begin{array}{l}\text { Bis }(O \text {-isoamyldithiocarbonato) } \\
\text { (3-bromopyridine)oxovanadium }(\mathrm{IV})\end{array}$} & $\begin{array}{l}\mathrm{VO}\left(\mathrm{S}_{2} \mathrm{COC}_{2} \mathrm{H}_{5}\right)_{2} \\
\quad\left(\mathrm{C}_{5} \mathrm{H}_{5} \mathrm{NBr}\right)\end{array}$ & 36.98 & 5.01 & 2.30 & 22.89 & 37.02 & 4.74 & 2.58 & 23.23 \\
\hline 3 & \multicolumn{2}{|c|}{$\begin{array}{l}\mathrm{Bis}(\mathrm{O} \text {-isoamyldithiocarbonato })(2- \\
\text { methoxylpyridine }) \text { oxovanadium }(\mathrm{IV})\end{array}$} & $\begin{array}{l}\mathrm{VO}\left(\mathrm{S}_{2} \mathrm{COC}_{5} \mathrm{H}_{11}\right)_{2} \\
\left(\mathrm{C}_{6} \mathrm{H}_{7} \mathrm{NO}\right)\end{array}$ & 42.78 & 4.99 & 2.40 & 24.74 & 43.03 & 5.77 & 2.78 & 25.50 \\
\hline 4 & \multicolumn{2}{|c|}{$\operatorname{Bis}(O$-isoamyldithiocarbonato) (4- } & $\begin{array}{l}\mathrm{VO}\left(\mathrm{S}_{2} \mathrm{COC}_{5} \mathrm{H}_{11}\right)_{2} \\
\left(\mathrm{C}_{7} \mathrm{H}_{7} \mathrm{NO}\right)\end{array}$ & 44.01 & 5.11 & 2.58 & 23.01 & 44.36 & 5.64 & 2.72 & 24.90 \\
\hline 5 & \multicolumn{2}{|c|}{$\mathrm{Bis}(\mathrm{O}$-isoamyldithiocarbonato $)$} & $\begin{array}{l}\mathrm{VO}\left(\mathrm{S}_{2} \mathrm{COC}_{5} \mathrm{H}_{11}\right)_{2} \\
\left(\mathrm{C}_{5} \mathrm{H}_{5} \mathrm{NO}\right)\end{array}$ & 41.11 & 5.38 & 2.05 & 25.12 & 41.80 & 5.50 & 2.80 & 26.23 \\
\hline 6 & \multicolumn{2}{|c|}{$\begin{array}{l}\text { Bis }(O \text {-isoamyldithiocarbonato) } \\
\text { (2-amino-3-methylpyridine)oxovanadium(IV) }\end{array}$} & $\begin{array}{c}\mathrm{VO}\left(\mathrm{S}_{2} \mathrm{COC}_{5} \mathrm{H}_{11}\right)_{2} \\
\left(\mathrm{C}_{6} \mathrm{H}_{8} \mathrm{~N}_{2}\right)\end{array}$ & 42.99 & 5.31 & 4.90 & 24.88 & 43.11 & 5.98 & 5.58 & 25.51 \\
\hline 7 & \multicolumn{2}{|c|}{$\begin{array}{l}\operatorname{Bis}(O \text {-isoamyldithiocarbonato) } \\
\text { (2-amino-4-methylpyridine) oxovanadium(IV) }\end{array}$} & $\begin{array}{c}\mathrm{VO}\left(\mathrm{S}_{2} \mathrm{COC}_{5} \mathrm{H}_{11}\right)_{2} \\
\quad\left(\mathrm{C}_{6} \mathrm{H}_{8} \mathrm{~N}_{2}\right)\end{array}$ & 42.89 & 5.01 & 4.87 & 24.34 & 43.11 & 5.98 & 5.58 & 25.51 \\
\hline 8 & \multicolumn{2}{|c|}{$\begin{array}{l}\operatorname{Bis}(O \text {-isoamyldithiocarbonato) } \\
\text { (2-amino-6-methylpyridine)oxovanadium(IV) }\end{array}$} & $\begin{array}{c}\mathrm{VO}\left(\mathrm{S}_{2} \mathrm{COC}_{5} \mathrm{H}_{11}\right)_{2} \\
\left(\mathrm{C}_{6} \mathrm{H}_{8} \mathrm{~N}_{2}\right)\end{array}$ & 42.78 & 5.12 & 4.90 & 24.81 & 43.11 & 5.98 & 5.58 & 25.51 \\
\hline & \multicolumn{11}{|c|}{$\begin{array}{l}\text { Table 2. Molar conductance and magnetic data of 1:1 adducts of bis(o-isoamyldithio-carbonato)oxovanadium(IV) with } \\
\text { substituted pyridines }\end{array}$} \\
\hline & \multirow{2}{*}{$\begin{array}{l}\text { S. } \\
\text { No }\end{array}$} & \multirow{2}{*}{\multicolumn{2}{|c|}{ Name of the adduct }} & & & & \multirow{2}{*}{\multicolumn{3}{|c|}{$\begin{array}{l}\text { Molar conductance } \\
\mathrm{Ohm}^{-1} \mathrm{~mol}^{-1} \mathrm{~cm}^{2}\end{array}$}} & \multicolumn{2}{|c|}{ Magnetic data } \\
\hline & & & & & & & & & & $\begin{array}{l}\mu_{\text {eff }} \\
\text { B.M }\end{array}$ & $\begin{array}{c}\text { Tempt } \\
\mathrm{K}\end{array}$ \\
\hline & 1 & Bis(O-amyldithiocarbonato)(2-bromo & opyridine)oxovanad & um(IV) & & & & 5.76 & & 1.82 & 298 \\
\hline & 2 & Bis(O-ethyldithiocarbonato)(3-bromo & yridine)oxovanadium & (IV) & & & & 6.09 & & 1.80 & 298 \\
\hline & 3 & $\mathrm{Bis}(\mathrm{O}$-isoamyldithiocarbonato $)(2-$ met & oxypyridine)oxovans & dium(IV & & & & 7.49 & & 1.75 & 298 \\
\hline & 4 & $\mathrm{Bis}(\mathrm{O}$-isoamyldithiocarbonato $)(4$-ace & lpyridine)oxovanadi & um(IV) & & & & 5.63 & & 1.73 & 298 \\
\hline & 5 & Bis(O-isoamyldithiocarbonato $)(3$-hyd & xypyridine)oxovana & $\operatorname{dium}(\mathrm{IV}$ & & & & 4.78 & & 1.78 & 298 \\
\hline & 6 & Bis(O-isoamyldithiocarbonato)(2-ami & $0-3$-methylpyridine) & oxovana & $\operatorname{dium}(\mathrm{I}$ & & & 3.45 & & 1.84 & 298 \\
\hline & 7 & Bis(O-isoamyldithiocarbonato $)(2-a m$ & o-4-methylpyridine) & oxovan & dium( & IV) & & 5.23 & & 1.86 & 298 \\
\hline & 8. & Bis(O-isoamyldithiocarbonato $)(2-a m$ & o-6-methylpyridine) & oxovan & dium( & & & 6.06 & & 1.78 & \\
\hline
\end{tabular}




\section{Physicochemical investigation}

The structures of the isolated complexes were established from their molar conductance measurements, magnetic susceptibility measurements, electronic and infrared spectral data. The results of these investigations are tabulated and discussed.

\section{Molar conductance measurement}

The molar conductance value of their millimolar solutions in DMF are found in the range of 3.48-7.54 $\mathrm{ohm}^{-1} \mathrm{~mole}^{-1} \mathrm{~cm}^{2}$. These values are lower than the values which can be expected for uni-univalent electrolytes in these solvents suggesting that these complexes are neutral and non-ionic in character (Table 2).

\section{Magnetic measurements}

The $\mathrm{VO}^{2+}$ cation, being $\mathrm{d}^{1}$ ion, possesses a spin only magnetic moment value of 1.73 B. $\mathrm{M}^{17}$ corresponding to one unpaired electron. The adducts of $(O$-isoamyldithiocarbonato $)$ oxovanadium(IV) exhibit magnetic moments in the range 1.79-2.13 B.M and the values of magnetic moments are presented in (Table 2). The values are in accordance with the paramagnetic nature of these adducts due to the presence of unpaired electron. It also suggests that the adducts of oxovanadium(IV) have octahedral geometry and are monomeric in nature. The higher value of magnetic moment may be due to the orbital contribution.

\section{Spectral studies}

\section{Infrared spectra}

The infrared spectra of the adducts of oxovanadium(IV)xanthates exhibit a strong band in the range $996-960 \mathrm{~cm}^{-1}$ which is attributed to the terminal $\mathrm{V}=\mathrm{O}$ bond. These values are within the range observed for monomeric $\mathrm{VO}^{2+}$ complexes ${ }^{18}$. In the present work a single sharp band of high intensity has been observed in all the complexes in the range of 1011$1035 \mathrm{~cm}^{-1}$ range. The appearance of only C-S band suggests symmetrical bidentate binding of the xanthate moiety. There is a positive shift of $10-30 \mathrm{~cm}^{-1}$ in comparison to the free ligands. This indicates that the xanthate ligand coordinates with the metal through sulfur atoms. Moreover, the complexes show a band in the region 1190-1220 $\mathrm{cm}^{-1}$ which is attributed to $v(\mathrm{C}-\mathrm{O})$ of xanthate moiety (Table 3$)$. The corresponding band in the ligand appeared at lower frequency. A comparison of the infrared spectral data of complexes with their respective adducts reveals that $\mathrm{V}=\mathrm{O}$ band in the parent complex $\left(1000-980 \mathrm{~cm}^{-1}\right)$ gets displaced to lower frequencies $\left(990-960 \mathrm{~cm}^{-1}\right)$ in the adducts ${ }^{19}$. This displacement can be attributed to the electronic donation of the base to the vanadium $(\mathrm{N}-\mathrm{V})$, which increases the electron density on the metal $d$-orbitals, and consequently the $\mathrm{p}_{\pi}-\mathrm{d}_{\pi}$ donation from oxygen atom to vanadium is expected to be reduced.

\section{Electronic spectra}

The electronic spectra of the adducts of oxovanadium(IV)xanthates with heterocyclic monodentate nitrogen bases, prepared in the present work, were recorded in dimethylformamide. The electronic spectra data of the adducts of oxovanadium(IV)bis(Oethyldithiocarbonate) show three bands in the range $12255-15935 \mathrm{~cm}^{-1}, 15925-19043 \mathrm{~cm}^{-1}$ and 22550-29265 $\mathrm{cm}^{-1}$ and are assigned to $\mathrm{e} \leftarrow \mathrm{b} 2$, b1 $\leftarrow$ b2 and a1 $\leftarrow$ b2 transitions respectively are presented in (Table 3 ). These bands are characteristic of oxovanadium(IV) complexes in octahedral environment ${ }^{19-20}$. 
Table 3. Electronic and vibrational spectral data of 1:1 adducts of bis( $O$-isoamyldithio-carbonato)oxovanadium(IV) with substituted pyridines

\begin{tabular}{|c|c|c|c|c|c|c|c|c|}
\hline \multirow[t]{2}{*}{$\begin{array}{l}\stackrel{\circ}{z} \\
\dot{n}\end{array}$} & \multirow[t]{2}{*}{ Name of the adduct } & \multicolumn{3}{|c|}{$\begin{array}{l}\text { Electronic spectral } \\
\text { data in } \mathrm{cm}^{-1}\end{array}$} & \multicolumn{4}{|c|}{$\begin{array}{l}\text { Vibrational spectral } \\
\text { data in } \mathrm{cm}^{-1}\end{array}$} \\
\hline & & $v 1$ & $v 2$ & v3 & $v(\mathrm{C}-\mathrm{S})$ & $v(\mathrm{C}-\mathrm{O})$ & $v(\mathrm{~V}=\mathrm{O})$ & $v(\mathrm{~V}-\mathrm{S})$ \\
\hline 1 & $\operatorname{Bis}(O$-iso & 12155 & 17740 & 23763 & 1038 & 1130 & 971 & 406 \\
\hline 2 & arbonato)(3-b & 12600 & 17344 & 24220 & 1047 & 1134 & 972 & 411 \\
\hline 3 & $\operatorname{Bis}(C$ & 14853 & 16965 & 24655 & 1030 & 1147 & 975 & 404 \\
\hline 4 & nato) $(4-a$ & 13885 & 18220 & 26430 & 1055 & 1158 & 972 & 409 \\
\hline 5 & $\operatorname{Bis}(C$ & 14790 & 17725 & 25780 & 1059 & 1140 & 961 & 420 \\
\hline 6 & bonato)(2-amino & 13360 & 16540 & 25620 & 1047 & 1130 & 974 & 410 \\
\hline & $\operatorname{Bis}(O$ & 14540 & 16770 & 24889 & 1032 & 1144 & 970 & 415 \\
\hline 8. & $\operatorname{Bis}(O$-isoamyldithiocarbonato)(2-amino-6-methylpyridine) oxovanadium(IV) & 14378 & 15987 & 25637 & 1029 & 1153 & 978 & 411 \\
\hline
\end{tabular}

Table 4. In vitro evaluation against Sclerotium Rolfsii, Mean Colony Diameter $=90 \mathrm{~mm}$

\begin{tabular}{|c|c|c|c|c|}
\hline 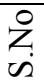 & Name of the adduct & $\begin{array}{c}\text { Concentration, } \\
\text { ppm }\end{array}$ & $\begin{array}{c}\text { Colony } \\
\text { diameter, mm }\end{array}$ & $\begin{array}{c}\% \text { inhibition } \\
(\mathrm{I})=[(\mathrm{C}-\mathrm{T}) / \mathrm{C}] \times 100\end{array}$ \\
\hline \multirow{4}{*}{\multicolumn{2}{|c|}{$1 \mathrm{Bis}(\mathrm{O}$-isoamylyldithiocarbonato)(3-bromopyridine)oxovanadium(IV) }} & 50 & 61.5 & 31 \\
\hline & & 100 & 22.7 & 75 \\
\hline & & 150 & 6 & 93 \\
\hline & & 200 & 1.5 & 98 \\
\hline \multirow{4}{*}{\multicolumn{2}{|c|}{$2 \mathrm{Bis}(\mathrm{O}$-isopropyldiithiocarbonato)(4-acetylpyridine)oxovanadium(IV) }} & 50 & 37.5 & 58 \\
\hline & & 100 & 18.5 & 79 \\
\hline & & 150 & 9.5 & 89 \\
\hline & & 200 & 2 & 98 \\
\hline \multirow{4}{*}{\multicolumn{2}{|c|}{$3 \mathrm{Bis}(\mathrm{O}$-isoamyldithiocarbonato)(3-hydroxy)oxovanadium(IV) }} & 50 & 23.7 & 73 \\
\hline & & 100 & 9.5 & 89 \\
\hline & & 150 & 2 & 98 \\
\hline & & 200 & 0 & 100 \\
\hline \multirow{4}{*}{\multicolumn{2}{|c|}{$4 \mathrm{Bis}(\mathrm{O}$-isoamyldithiocarbonato)(2-amino-3-methylpyridine) oxovanadium(IV) }} & 50 & 10 & 89 \\
\hline & & 100 & 5.6 & 93 \\
\hline & & 150 & 1.5 & 98 \\
\hline & & 200 & 0 & 100 \\
\hline
\end{tabular}




\section{Biological studies}

The antifungal activity of the adducts was tested by Poisoned food technique against the pathogenic fungus Sclerotium rolfsii. The linear growth of the fungus in controlled manner was recorded at different concentration of the adducts. The growth inhibition of Sclerotium rolfsii over control was calculated (Table 4). It is found that on increasing the concentration of the adducts, the colony diameter of the fungus decreases and hence percent inhibition increases (Figure 3$)^{21}$. The growth inhibition of Fungus over control was calculated as:

$$
\% \text { inhibition }(\mathrm{I})=\mathrm{C}-\mathrm{T} / \mathrm{C} \times 100
$$

Where $\mathrm{I}=$ percent inhibition, $\mathrm{C}=$ mean growth of fungus (in $\mathrm{mm}$ ) in control and $\mathrm{T}=$ mean growth of fungus (in $\mathrm{mm}$ ) in treatment.

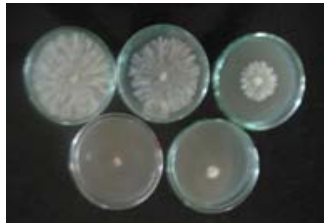

a

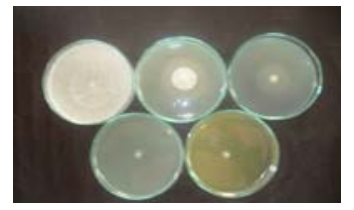

C

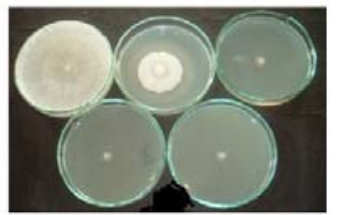

b

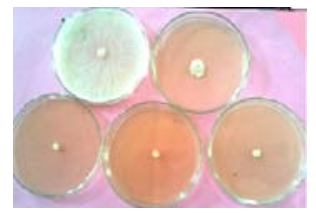

d

Figure 3. Antifungal activity of (a) $\mathrm{Bis}(\mathrm{O}$-isoamyidithiocarbonato)(3-bromopyridine) oxovanadium(IV), (b) $\operatorname{Bis}(O$-isoamyidithiocarbonato)(4-acetylpyridine)oxovanadium(IV), (c) $\operatorname{Bis}(O$-isoamyidithiocarbonato)(3-hydroxypyridine)oxovanadium(IV), (d) $\operatorname{Bis}(O$ isoamyidithiocarbonato)(2-amino-3-methylpyridine)oxovanadium(IV)

\section{Conclusion}

On the basis of above studies it is found that $1: 1$ adducts of $\mathrm{VO}(O \text {-isoamydithiocarbonato })_{2}$ have octahedral geometry. The complexes analyzed for the antifungal activity show considerable activity.

\section{References}

1. Coucouvanis D, In: Lippard S J, (Ed.), Progress in Inorganic Chemistry, Interscience, New York, 1970, 11, 233.

2. Eisenberg R, In: Lippard S J, (Ed.), Progress in Inorganic Chemistry, Interscience, New York, 1970, 12, 295.

3. Cras J A and Willemse J, In: Wilkinson G, Gillard R D and McCleverty J A, (Eds.), Comprehensive Coordination Chemistry, 1987, vol 2. Pergamon Press, Oxford, p-579.

4. Haiduc I, In: Mc Clevery J A and Mayer T J, Lever ABP (Eds.), Comprehensive Coordination Chemistry II, vol 1. Elsevier Pergamon, Amsterdam, 2004, p 349.

5. Formanek J, Holeckova H, Charewicz W, Walkowiak W and Gendolla T, Przem Chem., 1985, 64, 98-100.

6. Kotlyar D G and Tolley W K, Min Eng., 1995, 11, 1033-1039.

7. Gimeno M C, Jambrina E, Laguna A, Laguna M, Murray H H and Terroba R, Inorg Chim Acta, 1996, 249(1), 69-73; DOI:10.1016/0020-1693(96)05027-X 
8. Allen F H and Kennard O, Chem Des Autom News, 1993, 8, 31-37.

9. Victorriano L I and Cortes H B, J Coord Chem., 1996, 39(3-4), 231-239; DOI: $10.1080 / 00958979608024331$

10. Rao S R, Xanthates and Related Compounds, Chap. 1. Marcel Decker, New York, 1971.

11. Ara I, Bahij F E, Mohamed Lachkar and Najib Ben Larbi, Trans Met Chem., 2003, 28, 908-912; DOI:10.1023/A:1026326404549

12. Wang M, Zhang Q, Hao W and Zhong-Xi Sun, Chem Centr J., 2011, 5, 73.

13. Xiong R G, Yu Zh, Liu C M and You X Z, Polyhedron, 1997, 16(15), 2667-2671; DOI:10.1016/S0277-5387(96)00595-5

14. Gable R W, Hoskins B F and Winter G, Inorg Chem Acta, 1986, 96(2), 151-159; DOI:10.1016/S0020-1693(00)87575-1

15. Zelmon D E, Gebeyhu Z, Tomlin D C and Thomas M, Mater Res Soc Symp Proc., 1998, 519, 395.

16. Vogel A I, "A textbook of Quantitative Inorganic Analysis", ELBS, Longman, Green $\&$ Co. Ltd., London $4^{\text {th }}$ Edition, 1978, p678.

17. Rodgers G E, Introduction to Coordination, Solid State and Descriptive, Inorg Chem., McGraw-Hill: New York, 1996, p76.

18. Barracloug C G, Lewis J and Nyholm R S, J Chem Soc., 1959, 5, 3552.

19. Doadrio A.L, Sotelo J and Ruano A.F, Quim Nova., 2002, 25(4), 525-528.

20. Aswar A S, Bansod A D, Aswale S R and Mamdlik P R, Ind J Chem., 2004, 43(A), 1892.

21. Dharamraj N, Viswanathamurthi P and Natarajan K, Trans Met Chem., 2001, 26(1-2), 105-109; DOI:10.1023/A:1007132408648 